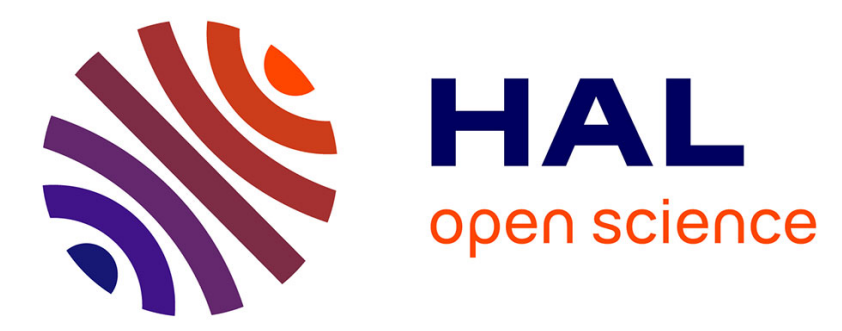

\title{
ANOMALOUS FREQUENCY AND TEMPERATURE DEPENDENCE OF THE OPTICAL ABSORPTION OF SMALL GOLD PARTICLES
}

\author{
U. Kreibig
}

\section{- To cite this version:}

U. Kreibig. ANOMALOUS FREQUENCY AND TEMPERATURE DEPENDENCE OF THE OPTICAL ABSORPTION OF SMALL GOLD PARTICLES. Journal de Physique Colloques, 1977, 38 (C2), pp.C2-97-C2-103. 10.1051/jphyscol:1977220 . jpa-00217059

HAL Id: jpa-00217059

https://hal.science/jpa-00217059

Submitted on 1 Jan 1977

HAL is a multi-disciplinary open access archive for the deposit and dissemination of scientific research documents, whether they are published or not. The documents may come from teaching and research institutions in France or abroad, or from public or private research centers.
L'archive ouverte pluridisciplinaire HAL, est destinée au dépôt et à la diffusion de documents scientifiques de niveau recherche, publiés ou non, émanant des établissements d'enseignement et de recherche français ou étrangers, des laboratoires publics ou privés. 


\title{
ANOMALOUS FREQUENCY AND TEMPERATURE DEPENDENCE OF THE OPTICAL ABSORPTION OF SMALL GOLD PARTICLES
}

\author{
U. KREIBIG \\ Fachrichtung 11.2 Experimentalphysik, Universität des Saarlandes \\ D-6600 Saarbriicken, Germany
}

\begin{abstract}
Résumé. - On a étudié les effets de taille dans des particules d'or $\left(10^{2}\right.$ à $10^{5}$ atomes/particules) préparées dans une matrice de verre. Des mesures d'absorption à 300 et $1,5 \mathrm{~K}$ dans le domaine spectral allant de 0,5 à $4,2 \mathrm{eV}$ ont mis en évidence trois effets lorsque la taille des particules diminue :

(i) La bande plasmon s'élargit ; la partie imaginaire de la constante diélectrique du matériau augmente.

(ii) La dépendance en température de la bande plasmon décroît.

(iii) Le seuil de transition interbande est décalé vers les basses énergies et la pente du bord de la bande diminue.

Les effets (i) et (ii) peuvent s'expliquer en supposant les niveaux électroniques discrets ; l'effet (iii) indiquerait un changement des paramètres du réseau et/ou un accroissement des transitions indirectes.
\end{abstract}

\begin{abstract}
Size effects have been studied in Au particles of various sizes $\left(10^{2}\right.$ to $10^{5}$ atoms/particle), which were prepared in a glass matrix. Absorption measurements at $300 \mathrm{~K}$ and $1.5 \mathrm{~K}$ in the spectral region from 0.5 to $4.2 \mathrm{eV}$ revealed three effects, when the particle size was reduced :

(i) The spherical surface plasmon band is broadened; the imaginary part of the dielectric constant of the particle material increases.

(ii) The temperature dependence of the plasmon band goes to zero.

(iii) The interband transition threshold is shifted to lower energies and the slope of the edge is diminished.

Effects (i) and (ii) can be explained by assuming discrete electron energy levels, effect (iii) points to lattice parameter changes and/or an increase of indirect transitions.
\end{abstract}

1. Introduction. - Special surface plasmon modes can be excited optically in small metallic particles [1-8]. Their investigation has become a widely accepted method in small particle physics [9-29, 49] and has revealed information concerning the transition from the molecular state to the bulky solid.

The first who observed size effects in the optical properties of Au particles and computed therefrom changes of the optical constants were v. Fragstein, Roemer and Schoenes [13] and Doremus [14]. Drastic changes of the plasmon band have also been found in $\mathrm{Ag}, \mathrm{Na}$ and $\mathrm{K}$ particles of less than about $10^{5}$ atoms/particle. Since the papers of Fröhlich [30] and Kubo [31] several calculations [32-37] explained these changes as due to discrete electronic states. They follow, however, as well from the classical model of electron mean free path limitations $[13,14,16,18,19]$. If there are quantized electronic states, also other solid state properties should be affected, e.g. the electronphonon scattering [32], which renders the optical properties of metals temperature dependent.

Most problematic in small particle physics is the particle preparation and no all-round convincing method has, yet, been found. Ensembles of well separated, isolated particles would be desirable; however, only a stabilization in a host medium prevents the particles from spontaneous coagulation, induced by the enormously high surface energy. So, we prepared small gold particles embedded in a glass matrix using photosensitive glasses $[38,11,12,14]$. Absorption spectra in the region of the plasma resonance absorption were recorded at various temperatures, and were evaluated in the way that was applied earlier to silver particles in photosensitive glasses $[18,19,40]$. First results are presented in the following. A more detailed report will be published elsewhere.

2. Experimental details. - Ensembles of nearly spherical, well separated particles with small size distributions $[11,14]$ were prepared in photosensitive glasses of the following compositions : $71.5 \%$ $\mathrm{SiO}_{2}, 23 \% \quad \mathrm{Na}_{2} \mathrm{O}, 4 \% \quad \mathrm{Al}_{2} \mathrm{O}_{3}, 1 \% \mathrm{ZnO}, \quad 0.3 \%$ $\mathrm{Sb}_{2} \mathrm{O}_{3}, 0.05$ to $0.13 \% \mathrm{CeO}_{2}, 0.004$ to $0.1 \% \mathrm{Au}$ in various compounds.

The particles grow during a tempering process which can be interrupted at any time, to record absorption spectra for particles with various sizes. The number of particles remains constant during the growth $[11,14]$. At $300 \mathrm{~K}$ a Zeiss double prism 
spectrophotometer was used in the spectral region from 0.5 to $4.2 \mathrm{eV}$. To determine temperature dependences, measurements were performed at $300 \mathrm{~K}$ and $1.5 \mathrm{~K}$ in the spectral region from 1.8 to $3.65 \mathrm{eV}$. Reflection and extinction losses of the glass matrix were eliminated with the aid of reference samples.

Relative mean particle sizes were determined (i) from the integral plasmon absorption, $K_{\max } d \Gamma_{1 / 2} \quad\left(K_{\max }\right.$ : absorption constant at the plasmon peak; $d$ : sample thickness ; $\Gamma_{1 / 2}$ : half halfwidth from the low frequency flank of the plasmon band), which was assumed to be proportional to the particle volume (e.g. 39), and (ii) from the measured absorption constant at the wavelength $\lambda=440 \mathrm{~nm}$. According to Doremus [14] and Roemer [13] the latter is proportional to the particle volume, irrespective of particle size in the investigated size region. Both methods imply a constant number of particles during the growth process.

Absolute particle sizes were evaluated from these relative values by adjusting them to particle sizes determined by Doremus [14]. From his results it follows a nearly linear dependence of the ratio $K_{\max } / K_{440}\left(K_{\max }\right.$ and $K_{440}$ : absorption constants at the plasmon band maximum and at $\lambda=440 \mathrm{~nm}$ ) on the particle radius $R$ between $2 R=2.5 \mathrm{~nm}$ and $2 R=6 \mathrm{~nm}$. However, our electron micrographs indicate Doremus' values to be somewhat too small, and more direct size determinations will therefore be necessary.

3. Optical plasmon excitation. - The total conduction electron absorption, extended in bulk metals and thin films from the plasma frequency to zero frequency is concentrated in small spherical particles in the narrow bands of special plasmon modes [40]. Advantageously, in the case of gold the plasmon band lies in the visible. Hence, absorption measurements of Au particles in this spectral region yield full information about changes of the selectron behaviour due to size effects.

For gold particles in glass the plasmon band lies at about $0.5 \mu \mathrm{m}$. In the region of longer wavelengths the absorption decreases to zero, following approximately a Lorentz profile. In the short wavelength region a nearly constant absorption contribution is caused by interband transitions. The interband transition edge is just covered by the plasmon band. Hence both, s-electron absorption and interband absorption could be studied with our absorption spectra of Au particles.

The absorption and dispersion spectra of small particles can be computed with the aid of the phenomenological theory of Mie, Gans and Happel $[1,41]$ using the complex dielectric constant $\varepsilon=\varepsilon_{1}+i \varepsilon_{2}$ of the particle material. They prove to be independent of particle size in the small particle region (diameters $2 R<10 \mathrm{~nm}$ ) if the dielectric constant of bulk gold is used. Hence, if measured absorption spectra of such particles exhibit any size dependence, it must be caused by deviations of the dielectric constant of the particle material from the bulk values.

4. Determination of $\varepsilon_{.}$- Spectra of the dielectric constant of the particle material were obtained by a Kramers Kronig analysis of the absorption data [40]. To extend the numerical integration in this procedure beyond the region of the experiments to the far U.V., the $\varepsilon$-spectra of Daniels [42] for $3.85 \mathrm{eV}$ to $30 \mathrm{eV}$ were used, without taking any possibly occuring size effect into account. Such effects, however, would influence our resulting spectra of $\varepsilon$ only slightly, since they are expected to remain small.

The determination of particle volume concentrations $C$ was done by comparing the measured absorption constant $K_{440}$ with the value $K_{440}\left(C=10^{-5}\right)=0.54 \mathrm{~mm}^{-1}$ following from Mie's theory with appropriate bulk optical constants. Moderate variations of $C$ did not change the characteristic features of the $\varepsilon$-spectra. So, the accuracy of this method appears sufficient.

5. Experimental results. - Figure 1 shows, as an example, the sequence of absorption spectra for one sample with gold particles of various mean particle sizes, taken at $300 \mathrm{~K}$. The upward shift of the spectra reflects the increase of the size of each

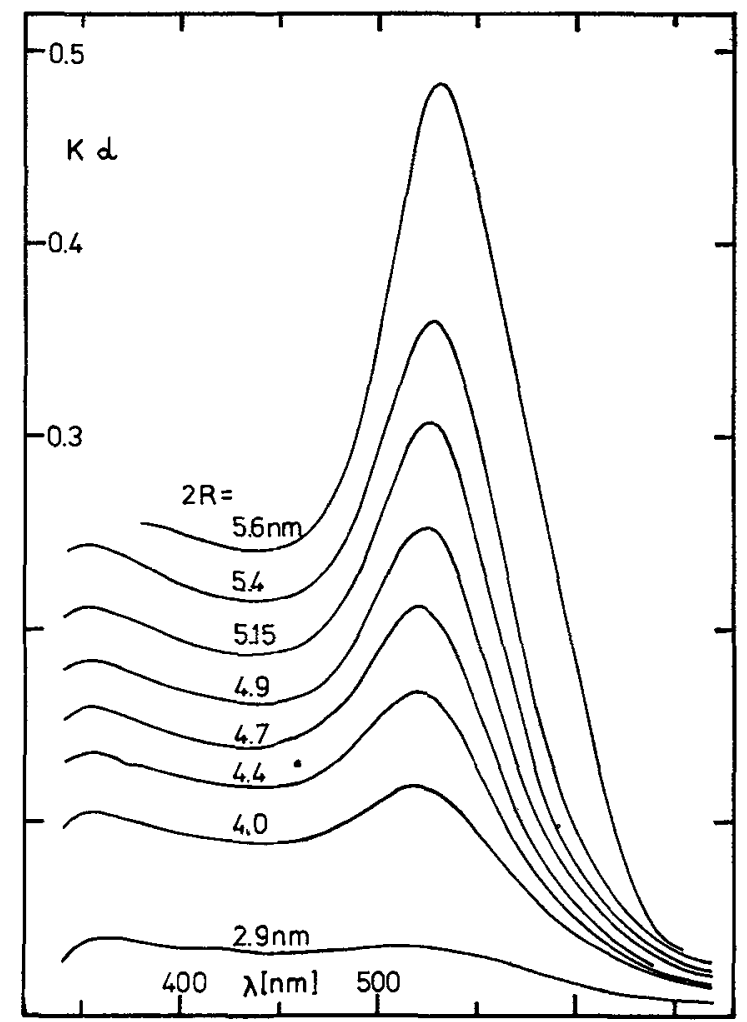

FIG. 1. - Experimental absorption spectra $(300 \mathrm{~K})$ of $\mathrm{Au}$ particles of various mean diameters $2 R$ embedded in glass. $(K$ : absorption constant; $d$ : sample thickness; $\lambda$ : wavelength). 
particle since the number of particles remained unchanged. With increasing size, the plasmon peak becomes smaller and more pronounced [13, 14].

Spectra of $\varepsilon_{1}$ and $\varepsilon_{2}$, evaluated from such absorption spectra are presented in figure 2. Drastic changes in, both, $\varepsilon_{1}$ and $\varepsilon_{2}$, due to the decrease of particle size are obvious. Comparing with earlier
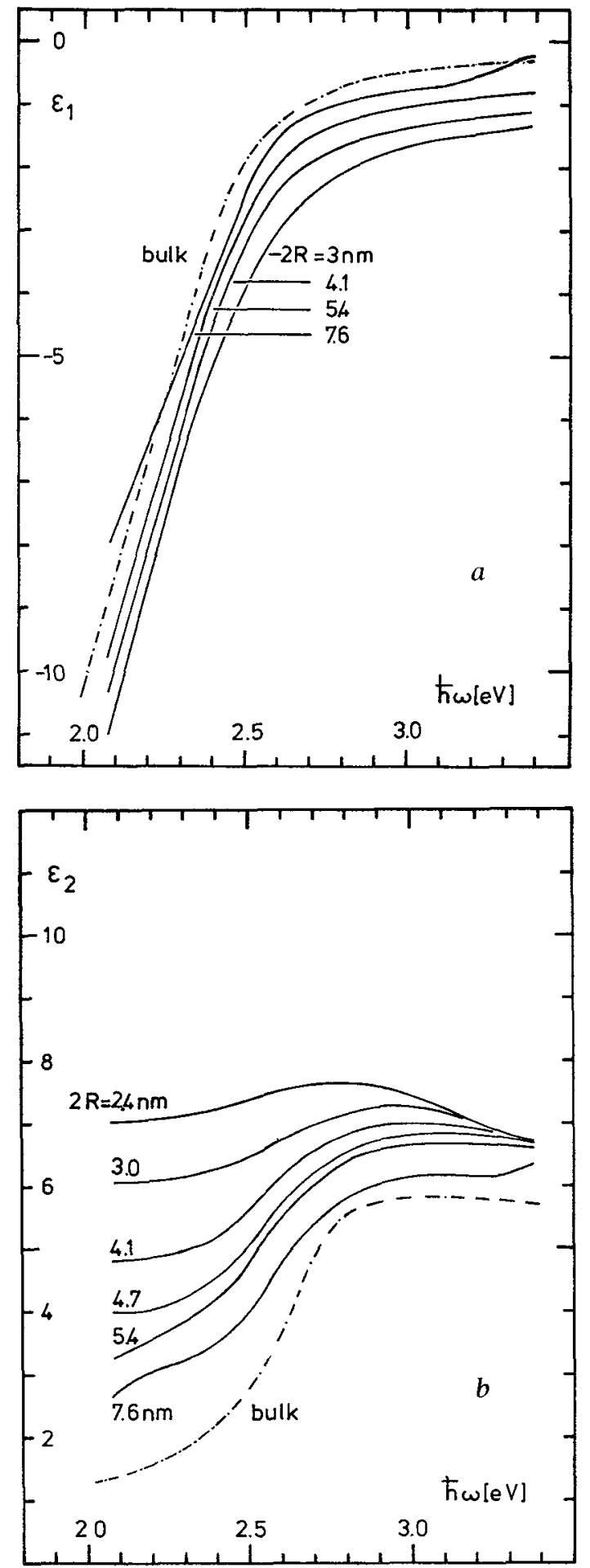

FIg. 2. - Spectra of the dielectric constant $\varepsilon_{1}+i \varepsilon_{2}$ for $\mathrm{Au}$ particles of various sizes as evaluated from measured absorption spectra by Kramers Kronig analysis. results from silver particles $[19,40]$, the changes of $\varepsilon_{2}$ are of about the same magnitude in the low frequency region, but they are smaller where interband transitions contribute. While in Ag particles $\varepsilon_{1}$ depends only slightly on size, there is a strong dependence in Au particles, especially in the interband region.

In figure 3 absorption spectra at $300 \mathrm{~K}$ and $1.5 \mathrm{~K}$ are compiled for 4 different particle sizes, which

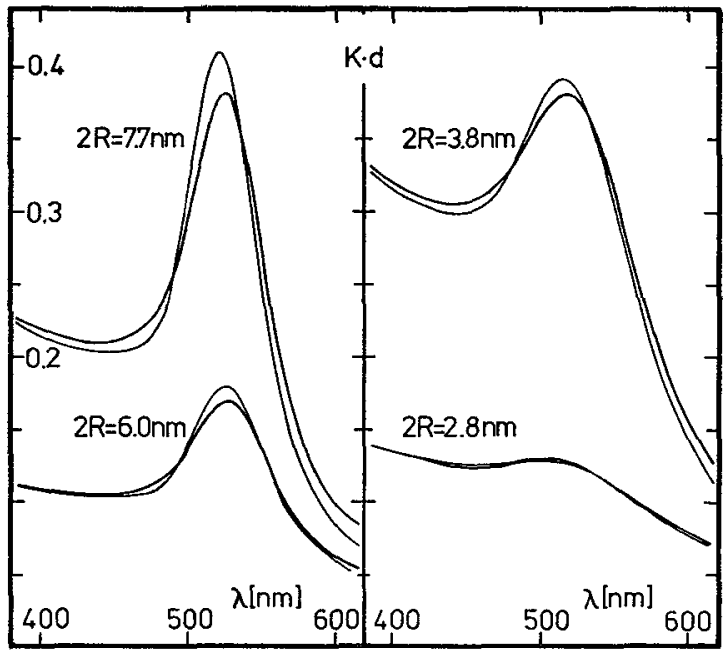

FiG. 3. - Absorption spectra at $300 \mathrm{~K}$ (solid lines) and $1.5 \mathrm{~K}$ (thin lines) of Au samples with various particle sizes. (Reflection and extinction losses due to the base glass are not eliminated).

clearly show that the temperature dependence of the plasmon peak decreases to smaller particles. This trend is confirmed for extremely small particles in figure 4.

6. Discussion. - Electron energy bands are split into discrete levels in small particles because of spatial limitation. It is unknown to which extent these levels are broadened in real metallic particles [19]. However, it seems accepted that in the conduction bands the broadening may be smaller than the mean distance of the levels, at least in particles consisting of less than, say, $10^{4}$ atoms, and thus the levels do not overlap.

Several calculations published recently show that the dielectric constant of particles with discrete levels exhibits a size dependence. According to ref. [36] $\varepsilon_{1}$ and $\varepsilon_{2}$ of one single particle are not smooth functions of frequency, but oscillate due to transitions between discrete eigenstates. For measurable absorption, samples with about $10^{10}$ to $10^{13}$ particles are required, which by no means can be produced with identical size and shape. Then the oscillations differ from particle to particle, and for the ensemble of particles an average $\varepsilon$ without such oscillations is obtained.

The further discussion will be restricted to the imaginary part $\varepsilon_{2}$ of the mean $\varepsilon$ since this quantity is local on the frequency scale, in contrast to $\varepsilon_{1}$. 


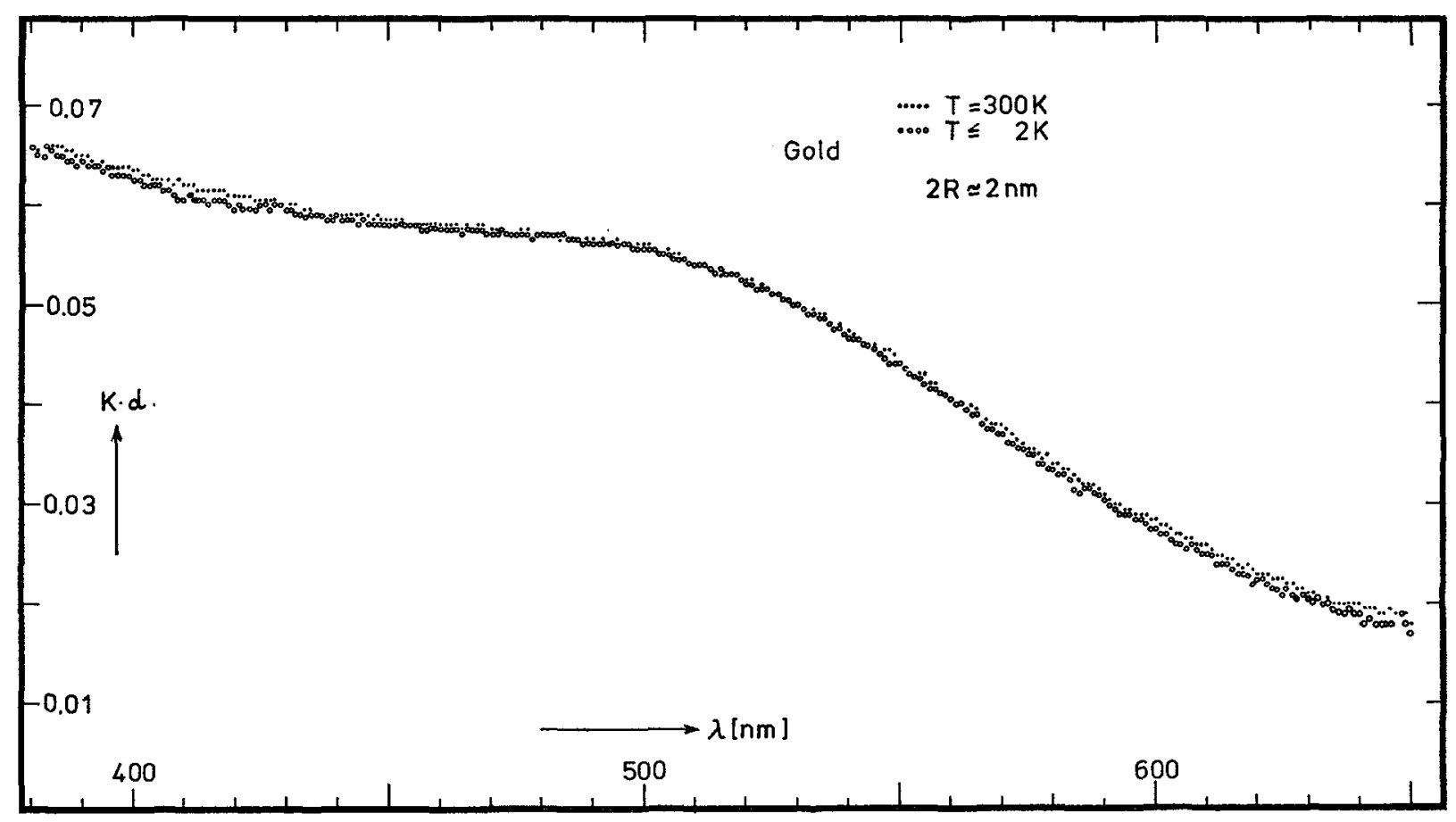

FIG. 4. - Absorption spectra at $300 \mathrm{~K}$ and $1.5 \mathrm{~K}$ of extremely small Au particles.

The size dependence of $\varepsilon_{2}$ due to the splitting up of the conduction band is given by

$$
\varepsilon_{2}(\omega, R)=\varepsilon_{2, \text { bulk }}(\omega)+\frac{A(\omega)}{R}
$$

( $\omega$ : frequency ; $R$ : particle radius)

where somewhat different functions $A(\omega)$ have been obtained by different authors [36, 37]. It should be mentioned that eq. (1) also follows from classical arguments for the case of a level broadening, large enough to produce a quasi continuous energy band (e.g. [19]).

In figure 5 experimental results for $\varepsilon_{2}$ of $\mathrm{Au}$ particles are summarized for one wavelength, and

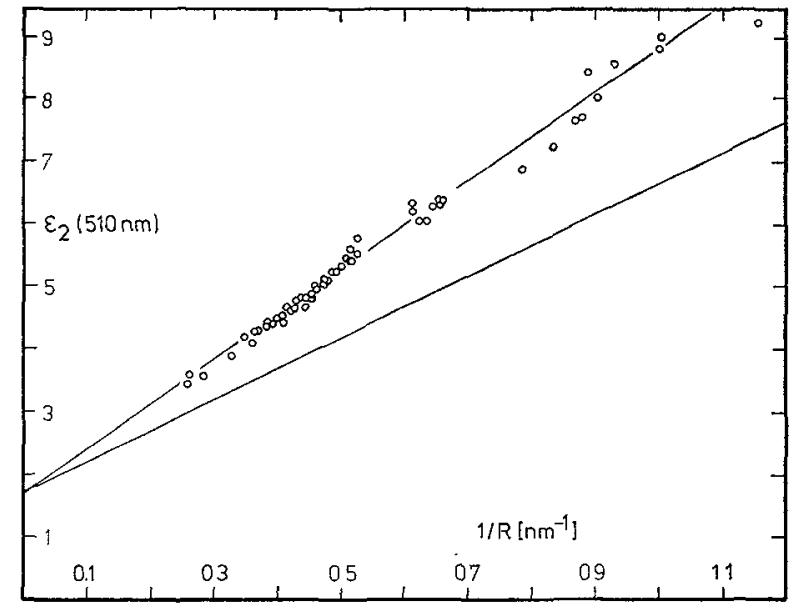

FIG. 5. - Imaginary part of the dielectric constant of Au particles at $510 \mathrm{~nm}$ wavelength, versus reciprocal particle radius. The points are from Kramers Kronig analysis of measured absorption. The lower straight line is calculated with eq. (1) (ref. [36]). they, in fact, show a linear dependence upon $1 / R$, as predicted by eq. (1).

An analogous size dependence, proportional to $1 / R$, has been calculated for the plasmon band width [36], and, again, the functional dependence of the experimental results confirm this prediction (Fig. 6) within the limits of accuracy.

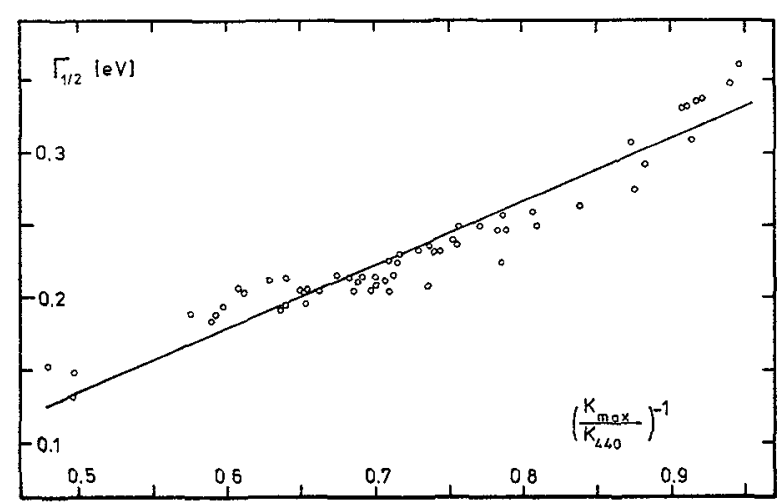

FIG, 6. - Plasmon band width of Au particles, versus reciprocal particle size. $\Gamma_{1 / 2}$ is the half halfwidth of the low energy flank. $\left(K_{\max } / K_{440}\right)$ is roughly proportional to the particle radius (see abscissa of figure 8 ).

The measured plasmon peak position revealed a size dependence, too, as shown in figure 7. It reflects the changes of $\varepsilon_{1}$ (Fig. 2) with particle size. Measurements with an Abbe refractometer showed that the refractive index $n_{0}$ of the matrix, which determines the peak position, varied slightly for different glass melts. These variations are, however, too small to explain fully the marked scatter in 


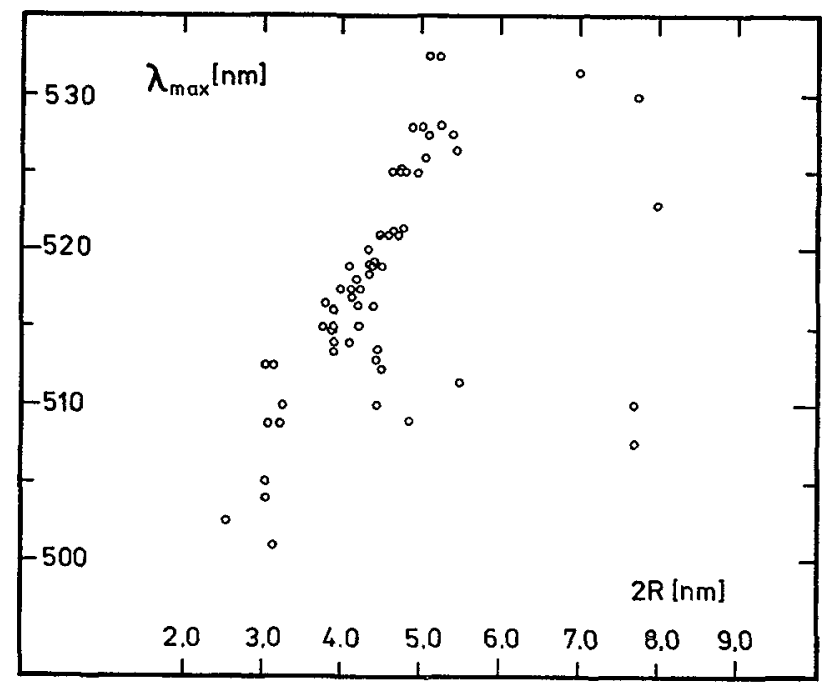

Fig. 7. - Plasmon peak position of Au particles, versus particle size. (For extremely small particles $(2 R<2.5 \mathrm{~nm})$ the band position could not be determined).

these experimental results. Yet, it cannot be excluded that in the surrounding of the particles $n_{0}$ differs from the mean $n_{0}$ of the sample. The sign of the peak shift is in agreement with our previous measurements on silver particles [36], but the shift is more pronounced. The sign differs from measurements of Smithard on silver particles [26] and calculations by Ascarelli and Cini [43].

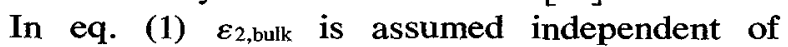
particle size. Generally, however, all absorption and dispersion processes contributing to the dielectric constant will be changed during the transition from the bulk metal to the molecule. Hence, the processes contributing to $\varepsilon_{2, \text { bulk }}$ of eq. (1) reveal size dependences, too, in sufficiently small particles. One among these is the electron phonon scattering which, in $\mathrm{Au}$, yields the main portion of the temperature dependence of $\varepsilon_{2}$ in the spectral region of our experiments. (Additional contributions arise from thermal lattice parameter changes.) The shape of the plasmon peak depends on $\varepsilon_{2}$, and so, measurements of the temperature dependence of the plasmon peak give information about this scattering process.

Kubo [32] predicted that the electron phonon scattering should be suppressed in small particles if the level spacing near the Fermi level exceeds the maximum phonon energy. Roughly estimated, this will happen in noble metal clusters of less than 250 atoms. Even in larger particles the interaction should be diminished because of the difficulty, arising from the discrete energy spectrum, to conserve, both, energy and wavevector. The wavevector selection rule causing this structure of the energy spectrum is only determined by the particle geometry, and in thermally isolated particles, it is identical for electrons and phonons. Thus the phonon spectra are discrete, too.
The lattice vibration spectra of embedded particles, however, are influenced by the coupling to the host matrix if the attenuation lengths of host phonons in the particles are no longer negligeable compared to the particle diameter. Then the spectra may contain essential features of the host matrix spectra and this may affect additionally the electron phonon scattering.

Our experiments show, in fact, a decrease of the temperature dependence of the absorption spectra towards smaller particles. Figure 8 gives the ther-

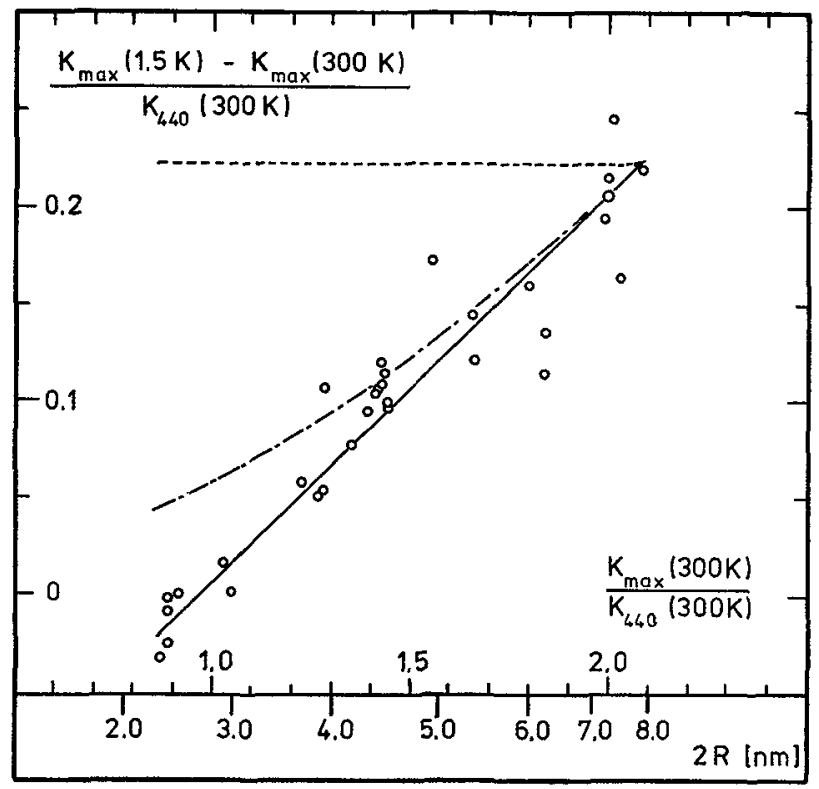

FIG. 8. - Changes of the absorption constant at the plasmon peak of $\mathrm{Au}$ particles by cooling from $300 \mathrm{~K}$ to $1.5 \mathrm{~K}$, versus particle size.

The broken line is calculated for size independent $\varepsilon$. The dash-dotted line is calculated for size dependent $\varepsilon_{2}$ [36], but size independent $\mathrm{d} \varepsilon_{2} / \mathrm{dT}$. Both curves are adjusted to the experimental value for $2 R=8 \mathrm{~nm}$.

mal changes of the plasmon peak hight versus the reciprocal particle radius, normalized to constant particle concentration. Making the rough assumption that $\mathrm{d} K_{\max } / \mathrm{d} T \simeq \Delta K_{\max } / \Delta T$ with $\Delta K_{\max }=K_{\max }(1.5 \mathrm{~K})-K_{\max }(300 \mathrm{~K})$ we can compare these results to some theoretical predictions. From Mie's theory follows [19] that $K_{\max }=$ const. $\left(\varepsilon_{2}\left(\lambda_{\max }\right)\right)^{-1}$ and thus the temperature dependence $\mathrm{d} K_{\max } / \mathrm{d} T$ is proportional to $\varepsilon_{2}^{-2}\left(\mathrm{~d} \varepsilon_{2} / \mathrm{d} T\right)$ and to $K_{\max }\left(\mathrm{d} \varepsilon_{2} / \mathrm{d} T\right)$, respectively.

Now three different cases can be distinguished :

(i) $\varepsilon_{2}$ and $\mathrm{d} \varepsilon_{2} / \mathrm{d} T$ are independent of the particle radius $R$. Then $\Delta K_{\max }$ is not influenced by $R$ (broken line in figure 8 ).

(ii) $\varepsilon_{2}$ depends on $R$ as given by eq. (1), but $\mathrm{d} \varepsilon_{2} / \mathrm{d} T$ is independent of $R$. Then $\Delta K_{\max }$ is proportional to $\left(K_{\max }(R)\right)^{2}$ (dash-dotted line in figure 8).

(iii) Both, $\varepsilon_{2}$ and $\mathrm{d} \varepsilon_{2} / \mathrm{d} T$ depend on $R$, as it is predicted by the discrete energy level model. Then 
the $R$-dependence of $\Delta K_{\max }$ is stronger than given by the dash-dotted curve in figure 8 .

Indeed, the experimental results in figure 8 show a stronger dependence upon size for $2 R<4 \mathrm{~nm}$ than given by the dash-dotted curve, going to $\Delta K_{\max }=0$ for $2 R=2.5 \mathrm{~nm}$, i.e. for particles with $5 \times 10^{2}$ atoms. This, probably, points to the existence of a quenching of the electron phonon scattering caused by level quantization. Earlier experiments on Ag particles [19] can be interpreted analogously. They proved to be influenced by thermal lattice changes and similar effects may occur in the gold particles.

Both size effects discussed above are concerning the s-electrons. The plasmons are hybrid ones in $\mathrm{Au}$, being shifted from the pure s-electron energy of about $10 \mathrm{eV}$ to about $2 \mathrm{eV}$ by the influence of the 5d-bands. Accidentally, the plasmon frequency thus coincides nearly with the threshold frequency for 5d-6s transitions. Since s-electron and interband contributions are additive in the dielectric constant, $\varepsilon=\varepsilon^{(s)}+\varepsilon^{(1)}, \quad \varepsilon^{(i)}$ of our gold particles could be obtained by subtracting the s-electron contribution from experimental $\varepsilon$-spectra. For this purpose we used the size dependent $\varepsilon^{(\mathrm{s})}$ as calculated in ref. [36] and [19]. Figure 9 shows some results for the imaginary part of $\varepsilon^{(i)}$.

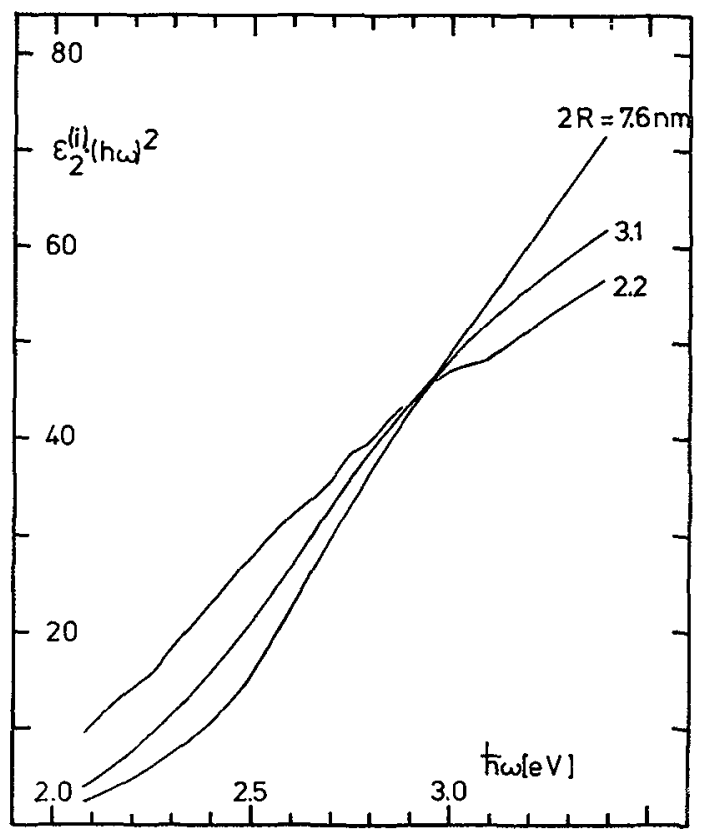

FIG. 9. - Size dependence of the interband transition edge in Au particles.

$\varepsilon_{2}^{(i)}$ is the interband part of $\varepsilon_{2}$ of figure $2.2 R$ is the particle diameter.

This evaluation implies problems concerning the precise determination of particle sizes and concentrations and so, figure 9 should show changes in the structure of the spectra rather than absolute values. These changes are a decrease of the slope of the interband transition edge and a slight shift to lower frequencies when the particles become smaller. Thus, the interband onset energy shifts from about $2.3 \mathrm{eV}$ in particles of $10^{4}$ atoms to $1.8 \mathrm{eV}$ in particles of about $5 \times 10^{2}$ atoms. In bulk gold the edge is due to direct transitions from $5 \mathrm{~d}$ bands to the Fermi level in the $6 \mathrm{~s}$ band around $\mathrm{L}$ (threshold energy: $2.38 \mathrm{eV}$ ) with a small contribution of transitions near X (threshold: $1.7 \mathrm{eV}$ ) [46].

In the smallest investigated particles more than half of the atoms form the particle surface, and, hence it is obvious to ascribe the size dependence of $\varepsilon_{2}^{(i)}$ in figure 9 to the surface atoms. They may cause changes of the electronic band structure and/or the interband transitions. Several effects are expected to influence the lattice potential at the surface, as reduction of the coordination number, interactions with host ions and lattice parameter changes, and it appears difficult to estimate their importance. Lattice contractions of the order of some percent compared to the bulk have repeatedly been reported ([44] and citations therein) for metallic particles. Investigations [45] of the surface atoms on (110)-planes of Al yielded changes of about $10 \%$ compared to the volume. For bulk gold Christensen and Seraphin [46] computed the effects of lattice constant changes on band structure and dielectric constant. They found that the interband transitions at the threshold are shifted by- $0.2 \mathrm{eV}$ if the lattice is contracted by $2 \%$. If we assume tentatively that a reduction of the lattice parameters at the surface of our particles is the only reason for the observed interband edge changes, the experimental results are consistent with a reduction of about $5 \%$. Then the threshold energies vary from the inner of the particles to the surface. The experiment gives a superposition of these contributions, and hence, a flattened band edge. This effect increases with increasing surface - to volume - ration, i.e. with decreasing particle size.

It appears unrealistic, however, that this effect should be the only one to influence the interband edge. For silver clusters of, say, 10 atoms, ESCA measurements [47] proved that the d-bands are narrowed and shifted compared to the bulk metal, probably due to a reduction of the number of neighbours of the surface atoms. An analogous effect should occur for the surface atoms of larger particles, which we investigated, and should result in a shift of the interband transition edge towards higher energies. Then the shift of the edge due to structural relaxation of the surface atoms may, at least partly, be compensated and the band structure may not be sufficiently changed to give an explanation for the experimental results.

Yet, not only the band structure but also the type of electronic transitions, involved in the optical absorption at the interband edge may be changed in particles. These transitions are direct ones in bulk gold. However, near the surface of a small particle 
this may not be true, if the surface contributes to the k-vector conservation. Such contributions of the surface are important for the optically excited transitions between discrete levels within a sizequantized energy band and are also known, e.g., from the optical excitation of nonradiative surface plasmons at rough surfaces. If such surface influences exist for interband transitions, too, then nonvertical $s-d$ transitions are expected in the gold particles below the energy of the onset of direct transitions. Their contribution increases with the surface - to volume - ratio, thus exhibiting a size dependence. An accurate inspection of the band structure of gold will be necessary to prove whether the probability of such transitions is large enough to explain our experimental results.

Acknowledgments. _- I am indebted to Pr. J. Friedel and to Pr. R. Kubo for discussions about nondirect transitions in small particles. The experimental assistance of $H$. Pressmann and Th. Gebhard is gratefully acknowledged.

\section{References}

[1] MIE, G., Annln. der Phys. 25 (1908) 377.

[2] Fujimoto, F., Komaki, K., J. Phys. Soc. Japan 25 (1968) 1679.

[3] Crowell, J., Ritchie, R. H., Phys. Rev. 172 (1968) 436.

[4] Kreibig, U., Zacharias, P., Z. Phys. 231 (1970) 128.

[5] Clanget, R., Optik 35 (1972) 180.

[6] Kokkinakis, T., Alexopoulos, K., Phys. Rev. Lett. 28 (1972) 1632

[7] Lushnikov, A., Simonov, A., Z. Phys. 270 (1974) 17

[8] Ruppin, R., Phys. Rev. B 11 (1975) 2781.

[9] GENZEL, L., Festkörperprobleme XIV; Vieweg, Braunschweig (1974) 183.

[10] Doyle, W. T., Phys. Rev. 111 (1958) 1067.

[11] Maurer, R. D., J. Appl. Phys. 29 (1958) 1

[12] Maurer, R. D., J. Chem. Phys. 31 (1959) 444.

[13] Fragstein, C. v., Roemer, H., Z. Phys. 151 (1958) 54. Roemer, H., Fragstein, C. v., Z. Phys. 163 (1961) 27. Fragstein, C. v., Schoenes, F. J., Z. Phys. 198 (1967) 477.

[14] Doremus, R. H., J. Chem. Phys. 40 (1964) 2389. Doremus, R. H., « Symp. on Nucl. and Cryst. in Glasses and Melts", Am. Ceram. Soc. Bull. (1962) 119.

[15] Doremus, R. H., J. Chem. Phys. 42 (1965) 414.

[16] Karlsson, A. V., BeCKMan, O., Solid State Commun. 5 (1967) 795.

[17] Kleemann, W., Z. Phys. 215 (1968) 113.

[18] Kreibig, U., Fragsteln, C. v., Z. Phys. 224 (1969) 307.

[19] Kreibig, U., J. Phys. F 4 (1974) 999.

[20] Jain, S. C., Sootha, G. D., Phys. Rev. 171 (1968) 1075.

[21] Jain, S. C., Arora, N. D., J. Phys. \& Chem. Solids 35 (1974) 1231 .

[22] JAIN, S. C., ARoRA, N. D., Solid State Commun. 15 (1974) 433.

[23] J AIN, S. C., ARORA, N. D., J. Phys. C 7 (1974) 3427.

[24] Jain, S. C., Arora, N. D., Chaudhary, K. L., J. Appl. Phys. 45 (1974) 2368.
[25] Smithard, M. A., Dupree, R., Phys. status solidi A 11 (1972) 695.

[26] Smithard, M. A., Solid State Commun. 13 (1973) 2, $153 ; 14$ (1974) 5,407 .

[27] Smithard, M. A., Tran, M. Q., Helv. phys. Acta 46 (1974) 869.

[28] Garniere, J. D., Rechsteiner, R., Smithard, M., Solid State Commun. 16 (1975) 113.

[29] Scheunemann, W., Jaeger, H., Z. Phys. 265 (1973) 441.

[30] Froehlich, H., Physica 6 (1937) 406.

[31] KuBo, R., $f$. Phys. Soc. Japan 17 (1962) 975.

[32] KuBo, R., Comments Solid State Phys. 1 (1968) 61.

[33] Kawabata, A., Kubo, R., J. Phys. Soc. Japan 21 (1966) 1765.

[34] Sander, L., J. Phys. \& Chem. Solids 29 (1968) 291

[35] Cini, M., Ascarelli, P., J. Phys. F 4 (1974) 1998.

[36] Genzel, L., Martin, T. P., Kreibig, U., Z. Phys. B 21 (1975) 339.

[37] RupPIN, R., YATOM, H., Phys. status solidi B 74 (1976) 647.

[38] STOOKEY, S. D., Ind. Eng. Chem. 41 (1949) 856.

[39] Kreibig, U., Appl. Phys. 10 (1976) 255.

[40] Kreibig, U., Z. Phys. 234 (1970) 307.

[41] Gans, R., HAPPEL, H., Annln. der Phys. 29 (1909) 277

[42] Daniels, J., Festenberg, C. v., Raether, H., ZePPENFELD, K., Springer Tracts of Modern Physics Vol. 54 (1970).

[43] Ascarelli, P., CinI, M., Solid State Commun. 18 (1976) 385.

[44] Schroeer, D., Marzke, R., Erickson, D., Marshall, S., WILENZICK, R., Phys. Rev. B 2 (1971) 4414

[45] Finnis, M. W., Heine, V., J. Phys. F 4 (1974) L37.

[46] Christensen, N. E., Seraphin, B. O., Phys. Rev. B 4 (1971) 3321 .

[47] Mason, M. G., Baetzold, R. C., J. Chem. Phys. 64 (1976) 271.

[48], WINSEMIUS, P., Dissertation Leiden (1973).

[49] Granqvist, C. G., Hunderi, O., Phys. Rev. B in press. 